\section{The Arctic sea-ice navigability index}

\author{
Mukesh Gupta \\ Université catholique de Louvain, Faculty of Sciences, \\ Earth and Life Institute, Georges Lemaître Centre for Earth and \\ Climate Research, Place Louis Pasteur 3, SC10-L4.03.08, \\ B-1348 Louvain-la-Neuve, Belgium
}

A rapidly changing sea-ice regime in the Arctic demands an index that could provide a priori information to icebreakers for hazard-free navigation through ice across the Arctic. This study presents a new sea-ice navigability index, solely based on daily available remote-sensing products. The index has a numerical scale from 0 to 100 that represents the navigability of icebreakers through sea ice. High mobility of sea ice implies that there may be fragmented ice floes that are susceptible to quick displacement, thus allowing an icebreaker to navigate through the ice.

Keywords: Icebreakers, navigability index, remote sensing, sea ice, shipping routes.

THE Arctic is going through unprecedented changes as is clear from the various observational data of the past several decades ${ }^{1}$. A considerable reduction in the sea-ice extent, thickness and volume has opened the opportunities for navigation in the Arctic Ocean. These are of paramount importance for commercial ship routes, scientific expeditions, and recreational cruises ${ }^{2}$. Smith and Stephenson ${ }^{3}$ have presented model-based projections for shipping routes in the Arctic. It would be convenient for the navigators to have a daily and Arctic-wide index that could provide them a priori information on a probable route through the Arctic Ocean with the least trouble of navigation, or if the route is navigable. Such an index can help the navigators to assess the risks associated with sailing in the ice-covered waters. This study proposes, a remote sensing-based sea-ice navigability index using which it is possible to generate Arctic-wide daily maps of sea-ice navigability.

Navigability in the Arctic Ocean is possible under two conditions: (1) the amount of ice is negligible (or less than $15 \%$ ice concentration), and (2) thin sea ice (about $1 \mathrm{~m}$ ice thickness) is present with up to about $100 \%$ ice concentration. Most previous studies have only discussed the projections of the former possibility of an ice-free Arctic Ocean ${ }^{4}$. Liu et al. ${ }^{5}$ and $\mathrm{Yu}$ et al. ${ }^{6}$ described the possibility of navigability in the Northwest and Northeast Passages using satellite-based ice-concentration products. Due to the changing sea-ice regime in the Arctic, it is now possible to navigate through the ice-covered regions because the sea-ice thickness has declined ${ }^{7}$. However, only the Polar Class ships can navigate through sea ice.

e-mail: guptm@yahoo.com
This study presents an index on a numerical scale of 0 100 to assess navigability through Arctic sea ice solely using remote-sensing data products.

The fundamental premise in defining an index for navigability is whether there is unbreakable (or breakable) sea ice in the path of icebreakers. Some important geophysical variables responsible for determining if the icebreakers can easily break the ice are ice strength, ice drift, ice thickness, ice concentration, melt pond fraction, and whether the ice is fast or pack ice. Other primary factors that influence ice motion and navigation are atmospheric factors (air temperature, surface winds) and oceanic factors (swell, ocean circulation). It is much easier to navigate during summer as the ice is weaker and often laden with melt ponds. Sea-ice thickness, as we know, has significantly reduced throughout the Arctic, except in the perennial sea-ice regions, e.g. Canadian Arctic Archipelago, and fast ice regions of the circumpolar Arctic. So, this work assumes that ice thickness may not be of concern in most regions of the Arctic Ocean for sea-ice navigability. The ability of sea ice to move, i.e. ice drift or ice motion circumvents the inconvenience caused by ice strength in an easy sail through sea ice. Ice concentration and ice motion vectors are of importance for assessing the navigability in ice-covered regions.

The AMSR-E/AMSR-2 unified L3 daily ice concentration product, version 1 at $25 \mathrm{~km}$ spatial resolution is the most suitable for this study ${ }^{8}$. These products are available for download in polar grid from https://nsidc.org/data/ AU_SI25/versions/1/. Polar Pathfinder daily $25 \mathrm{~km}$ EASE-grid sea ice motion vectors, version 4, uses satellite data, buoy data and model forecasts to generate daily ice motion vectors ${ }^{9}$. The ice velocities are available for download from https://nsidc.org/data/NSIDC-0116/ versions/4/. The mean difference between the interpolated $u$ components and the buoy vectors was $0.1 \mathrm{~cm} \mathrm{~s}^{-1}$ with a root mean square (RMS) error of $3.36 \mathrm{~cm} \mathrm{~s}^{-1}$. For the $v$ component, the mean was $0.4 \mathrm{~cm} \mathrm{~s}^{-1}$ with an RMS error of $3.40 \mathrm{~cm} \mathrm{~s}^{-1}$ (ref. 8 ).

To determine the probable passage for icebreakers through sea ice, it is important to determine if the icecovered region is mobile; and if the ice is mobile, how much volumetric flux of sea ice passes through per reference grid area $\left(625 \mathrm{~km}^{2}\right.$ in this study). This flux of sea ice provides the basis for defining the sea-ice navigability index (eq. 1).

$$
\psi=\frac{1}{k} A|\boldsymbol{u}|
$$

where $\psi$ is the sea-ice navigability index on a scale of $0-100, A$ the sea ice concentration and $\boldsymbol{u}$ is the sea ice velocity, $|\boldsymbol{u}|=\sqrt{\left(u^{2}+v^{2}\right)}\left(\mathrm{cm} \mathrm{s}^{-1}\right)$. Here, $u$ is the $x$ component and $v$ is the $y$-component of ice velocity in the Cartesian coordinate system. The sea-ice concentration represents the reference grid area. $k$ is the navigability 
normalization factor whose value is $30 \mathrm{~cm} \mathrm{~s}^{-1}$ for a maximum sea-ice velocity of $30 \mathrm{~cm} \mathrm{~s}^{-1}$ for index values scaling from 0 to 100 .

It is interesting to observe how the index responds under two contrasting seasonal ice regimes, i.e. 28 April 2019 , which is about the time of the year when sea ice in the Arctic is most rigid and hard-frozen; and 14 September 2019, when the ice goes through the annual minimum ice extent/volume (Figure 1). The choice of these two dates represents the harshest and easiest navigational experiences by ships in the ice-covered Arctic Ocean. It is noticeable here that the sea-ice navigability index does an exclusive assessment of sailing prospects during the ice-covered seasons in the Arctic, covering the two extreme scenarios (peak of winter and start of freeze-up). However, ships other than icebreakers can navigate, if possible, through open-water areas of the Arctic Ocean during other seasons, e.g. summer seas, through polynyas, leads and so forth. The results show that there are considerable prospects for icebreakers to sail across the North Pole in both seasons, with little or no hassles.

The quantity of ice flux that passes through an area of $625 \mathrm{~km}^{2}$ determines the navigability in sea ice according to eq. (1). The more ice flux available, more is the possibility of sea-ice vulnerability. If the flux of ice is zero, it indicates that sea ice is not moving and regardless of ice thickness it might be risky to navigate through it. In eq. (1), the ice concentration lies between $80 \%$ and $100 \%$. Zero or low ice concentration indicates that sufficient open water is available and there should be little or no difficulty in navigation; therefore, the sea-ice navigability index only assesses the possibility when sea-ice concentration is high. Another condition for the derivation of sea-ice navigability index is that the reduced multiyear ice in the Arctic facilitates access to those regions that were earlier inaccessible. Thus, the underlying observation-based assumption is that the Arctic ice cover primarily comprises first-year ice (less than about $1.5 \mathrm{~m}$ thickness) and second-year ice (about $2 \mathrm{~m}$ thickness). The ice velocity is almost zero in the perennial ice zones or fast ice regions (Figure 1); therefore, the sea-ice navigability index is close to zero for such regions.
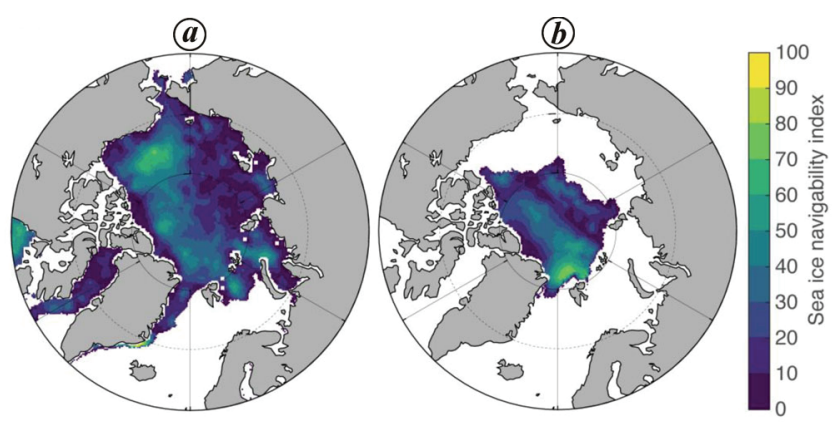

Figure 1. Sea ice navigability index on a scale from 0 (low navigability) to 100 (high navigability): $\boldsymbol{a}, 28$ April 2019 and $\boldsymbol{b}, 14$ September 2019.
A typical sea-ice velocity range in the Arctic Ocean is from 10 to $100 \mathrm{~cm} \mathrm{~s}^{-1}$ (ref. 10). An ice velocity of $10 \mathrm{~cm} \mathrm{~s}^{-1} \approx 10 \mathrm{~km} \mathrm{day}^{-1}$; therefore, on a grid of $25 \mathrm{~km} \times$ $25 \mathrm{~km}$ it would take about 2-3 days for ice to move completely out of the grid. In this study, careful consideration of the maximum ice velocity is $30 \mathrm{~cm} \mathrm{~s}^{-1}$. Occurrences of very high ice velocity (e.g. $100 \mathrm{~cm} \mathrm{~s}^{-1}$ ) are rare in the Arctic and these mostly result during severe storms or when underlying currents drive the ice floes. A maximum ice velocity of $30 \mathrm{~cm} \mathrm{~s}^{-1}$ is most suitable for developing a numerical scale of 0 to 100 for the sea-ice navigability index. Sea ice also experiences the Coriolis force besides air and water stresses (drag). This study, therefore, uses the resultant ice velocity vector, which thus covers all direct and indirect factors that contribute to ice movement. It is possible to have the upper bound of ice velocity as $100 \mathrm{~cm} \mathrm{~s}^{-1}$ with another value of $k$ in eq. (1). However, this choice may introduce a bias in the scale because of the rare occurrences of very high ice velocity in the Arctic Ocean.

Figure 2 shows the sea-ice navigability index for varying ice concentrations $(80-100 \%)$ and ice velocities $(0-$ $30 \mathrm{~cm} \mathrm{~s}^{-1}$ ). It is clear from the figure that immobile ice has zero navigability index. As the ice velocity increases, the slope of the line increases (shown by increasing line width - a thicker line indicates a higher velocity). Sea-ice volumetric flux is low (high) for low (high) ice concentration; but this does not imply that the navigability index should be low (high), because the navigability index is directly proportional to the ice concentration according to eq. (1). The index will be low only if both the ice velocity and ice concentration are low (Figure 2). This supports the premise of the study that high sea-ice velocity results in high ice volumetric flux in an area making the ice susceptible to breaking into smaller floes or drifting away

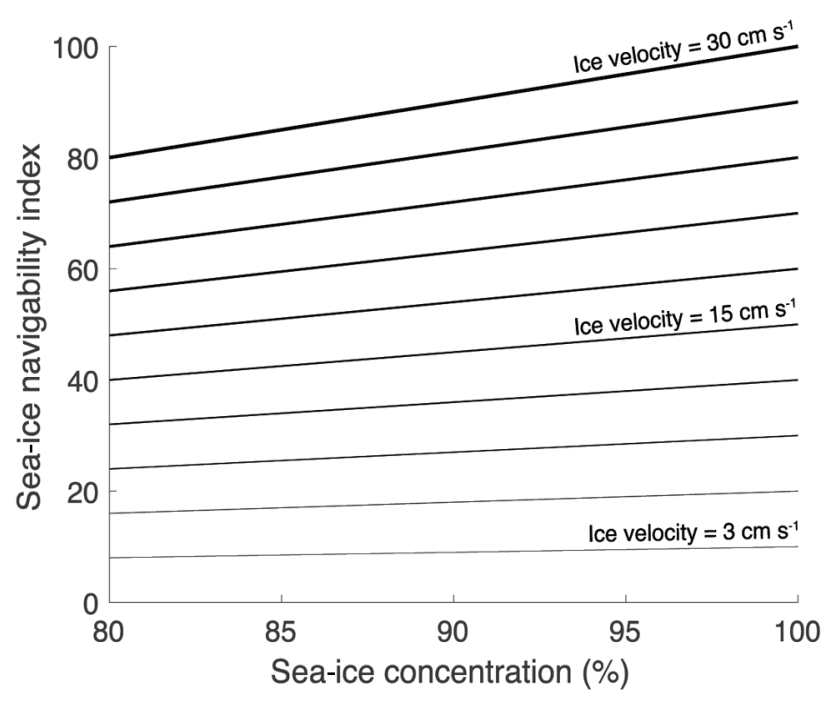

Figure 2. Sea-ice navigability index curves for varying ice concentrations and ice velocities (interval $=3 \mathrm{~cm} \mathrm{~s}^{-1}$ ).

CURRENT SCIENCE, VOL. 121, NO. 4, 25 AUGUST 2021 
by the icebreakers. Figure 2 also shows that sea-ice concentration has a much smaller impact on the ice navigability index compared to ice velocity.

Recent observational evidence of sea-ice navigability during summer across the Central Arctic is from the first Chinese trans-Arctic voyage ${ }^{11}$. The expedition by $M V$ Xue Long, a Chinese icebreaker, took place in the summer of 2012. It entered the Arctic from the Bering Strait and reached Iceland via the Northeast Passage, and returned to the Bering Strait via the Central Arctic. This shows that it is easy for an icebreaker to navigate through the ice in the Central Arctic because it is weak, has less internal strength due to continued thinning over several decades, and is more mobile than before. The sea-ice navigability index presented here is not a navigation index for open waters suitable for many ships. Sea-ice navigability is separate from open-water navigability, which implies different conditions and challenges for navigation in the Arctic. 'The navigation usually means navigation through open waters', and ice is an obvious obstruction to navigation. Therefore, the definitions of navigability and sea ice navigability index should remain neutral to subjective evaluation.

Under a changing Arctic sea-ice regime, the sea-ice navigability index can be an important tool for studying the changing underwater currents and their pattern, freshwater movement, flora and fauna migration, intrusion of Atlantic warm water into the Arctic Ocean, and ocean circulation, among others. The index is likely to serve as a standard measurement of sea-ice navigability against which comparison between many contributing physical factors to ice navigability is possible. It will also help understand how various contributing factors to seaice motion impact sea-ice navigability in the Arctic.

Sea ice drifts in the ocean because of several forces acting on it, as described earlier. The sea-ice navigability index takes the resultant ice motion as input, thus indirectly considering all factors that cause the ice to move. Here, the individual contribution of all those forces acting on an ice floe should be a part of the study. It is an assumption that ice thickness, despite consistent reduction over several decades throughout the Arctic, is about $1 \mathrm{~m}$, which may not be the case. Some thick ice floes (over $1 \mathrm{~m}$ ) are easy to break, whereas some thin ice floes (about $1 \mathrm{~m}$ ) are difficult to break. It depends on the internal strength of ice, which lies outside the scope of the present study. The navigational experience is also heavily dependent on the ambient atmospheric conditions that change rapidly over the time in which sea ice moves out of the grid of $25 \mathrm{~km} \times 25 \mathrm{~km}$. An integrated index for navigability in open waters and sea-ice navigability combined with concurrent wind and ice thickness information may improve the choice of the route through ice.

This study presents a new sea-ice navigability index based on daily available remote-sensing products. The index has a numerical scale from 0 to 100 that represents the navigability of icebreakers through sea ice. The current sea-ice regime in the Arctic is thinner and weaker than before, which demands an index that could provide a priori information to icebreakers for hazard-free navigation through ice across the Arctic. This index has its basis on the premise that ice volumetric flux passing through an area determines if that area is/can be navigable by icebreakers. It requires sea-ice concentration and ice velocity information in that area. High mobility of sea ice implies that there may be fragmented ice floes that are susceptible to quick displacement, thus allowing an icebreaker to navigate through the ice. The sea-ice navigability index is high when it is easy to displace ice out of the track of the icebreaker, or break it into smaller ice floes.

The occurrences of multiyear ice and fast ice (hurdles for sea ice navigability) in the Arctic have reduced and their geographic locations are known (e.g. Canadian Arctic Archipelago), thus making it easier for the icebreakers to avoid navigation in those regions. In the regions of all other ice occurrences, the sea-ice navigability index can serve as a useful tool for icebreakers to choose the track with least hurdles through sea ice. Daily maps of sea-ice navigability index are easy to prepare from the proposed formula. Transportation via the Arctic is likely to increase in the near future, and therefore, the navigators must keep in mind the serenity and pristine environment of the North Polar region.

Conflict of interest: The author declares no conflict of interest.

1. Box, J. E. et al., Key indicators of Arctic climate change: 19712017. Environ. Res. Lett., 2019, 14(4), 045010.

2. Aksenov, Y., Popova, E. E., Yool, A., Nurser, A. G., Williams, T. D., Bertino, L. and Bergh, J., On the future navigability of Arctic sea routes: high-resolution projections of the Arctic Ocean and sea ice. Mar. Policy, 2017, 75, 300-317.

3. Smith, L. C. and Stephenson, S. R., New trans-Arctic shipping routes navigable by midcentury. Proc. Natl. Acad. Sci. USA, 2013, 110(13), E1191-E1195.

4. Diebold, F. X. and Rudebusch, G. D., Probability assessments of an ice-free Arctic: comparing statistical and climate model projections. J. Econom., 2021; doi:10.1016/j.jeconom.2020.12.007.

5. Liu, X. H., Ma, L., Wang, J. Y., Wang, Y. and Wang, L. N., Navigable windows of the Northwest Passage. Polar Sci., 2017, 13, 91-99.

6. Yu, M., Lu, P., Li, Z., Li, Z., Wang, Q., Cao, X. and Chen, X., Sea ice conditions and navigability through the Northeast Passage in the past 40 years based on remote-sensing data. Int. J. Digit. Earth, 2020, 1-20; doi:10.1080/17538947.2020.1860144.

7. Kwok, R., Arctic sea ice thickness, volume, and multiyear ice coverage: losses and coupled variability (1958-2018). Environ. Res. Lett., 2018, 13(10), 105005.

8. Markus, T., Comiso, J. C. and Meier, W. N., AMSR-E/AMSR2 Unified L3 Daily $25 \mathrm{~km}$ Brightness Temperatures \& Sea Ice Concentration Polar Grids, Version 1. NASA National Snow and Ice Data Center Distributed Active Archive Center, Boulder, Colorado, USA, 2018; doi:https://doi.org/10.5067/TRUIAL3WPAUP (accessed on 12 February 2021). 
9. Tschudi, M., Meier, W. N., Stewart, J. S., Fowler, C. and Maslanik, J., Polar Pathfinder Daily $25 \mathrm{~km}$ EASE-Grid Sea Ice Motion Vectors, Version 4. NASA National Snow and Ice Data Center Distributed Active Archive Center, Boulder, Colorado USA, 2019; doi:https://doi.org/10.5067/INAWUWO7QH7B (accessed on 12 February 2021).

10. Leppäranta, M., The Drift of Sea Ice, Springer, Science \& Business Media, Berlin, Germany, 2011.

11. Luo, W., Yue, Z., Jianmin, L. and Shuqin, H., China's first transArctic voyage and related expectations. Adv. Polar Sci., 2014, 26(2), 276-284

ACKNOWLEDGEMENTS. I thank the National Snow and Ice Data Center for ice motion and ice concentration data. This research received no external funding.

Received 21 March 2021; revised accepted 7 July 2021

doi: $10.18520 / \mathrm{cs} / \mathrm{v} 121 / \mathrm{i} 4 / 567-570$

\section{Characterization of granulosis viruses of sugarcane early shoot borer, Chilo infuscatellus (Snell.) and internode borer, Chilo sacchariphagus indicus (Kapur)}

\author{
M. Kannan ${ }^{1}$, N. Geetha ${ }^{2}$, K. Elango ${ }^{3}$, M. Mohan ${ }^{4}$ \\ and G. Sivakumar ${ }^{4, *}$ \\ ${ }^{1}$ Nano Science and Technology, Tamil Nadu Agricultural University, \\ Coimbatore 641 003, India \\ ${ }^{2}$ ICAR-Sugarcane Breeding Institute, Coimbatore 641 007, India \\ ${ }^{3}$ Imayam Institute of Agriculture and Technology, \\ Tiruchirappalli 621 206, India \\ ${ }^{4}$ ICAR-National Bureau of Agricultural Insect Resources, Hebbal, \\ Bengaluru 560 024, India
}

A study was undertaken to characterize the granulosis viruses (GVs) of early shoot borer, Chilo infuscatellus (Snell.) (Crambidae: Lepidoptera) and internode borer, Chilo sacchariphagus indicus (Kapur) (Lepidoptera: Crambidae) in sugarcane. Scanning electron photomicrographs revealed ovo-cylindrical occlusion bodies (OBs) of GVs in early shoot and internode borers with an average size of 425.03 and $230.21 \mathrm{~nm}$, 387.64 and $208.68 \mathrm{~nm}$ in length and breadth respectively. Transmission electron photomicrographs also showed ovo-cylindrical OBs embedded with a rodshaped virion. The average length and breadth of the virion in the $O B$ was $271.0 \times 52.6 \mathrm{~nm}, 257.0 \times 50.2 \mathrm{~nm}$

*For correspondence. (e-mail: sivakumarg.nbaii@gmail.com) for early shoot and internode borer GVs respectively. Toxicity studies with the respective GVs revealed lethal concentration values of $4.38,4.61,6.89 \mathrm{OBs} / \mathrm{mm}^{2}$ and $1.85,135.43,8045.27 \mathrm{OBs} / \mathrm{mm}^{2}$ to second, third and fourth larval instars of Chilo infuscatellus granulosis virus (ChinGV) and Chilo sacchariphagus indicus granulosis virus (ChsaGV) respectively.

Keywords: Early shoot borer, granulosis viruses, internode borer, occlusion bodies, sugarcane, toxicity.

INSECT pests are the key constraint in sugarcane production as they damage all stages of the crop. Early shoot borer, Chilo infuscatellus Snellen and internode borer, Chilo sacchariphagus indicus (Kapur) are the most economic pests of sugarcane in India and cause 33\%, 35\% in yield and 3\%, 3.07\% in sugar recovery respectively ${ }^{1}$. C. infuscatellus is commonly known as shoot borer in the North Indian sugarcane belt and as early shoot borer in peninsular India ${ }^{2}$. High usage of chemical insecticides in its management has led to changes in the biology and reproductive potential of the pest and development of insecticide resistance ${ }^{3}$. The microbial biopesticide, granulosis virus $(\mathrm{GV})$ belonging to the Baculoviridae family is an effective alternative for managing sugarcane borers. Natural occurrences and high pathogenicity of Chilo infuscatellus granulosis virus (ChinGV) and Chilo sacchariphagus indicus granulosis virus (ChsaGV) to all the larval instars, post-larval stages under laboratory and field conditions have been reported by several workers ${ }^{4-6}$. Laboratory studies proved that early instars of internode borer were more susceptible to $\mathrm{GV}$ than late instars. First and second instar larvae were found to be highly susceptible to ChinGV and mortality ranged from $61.9 \%$ to $100 \%$ (ref. 5). Detailed information is not available on the characterization of GVs infecting sugarcane borers. Thus in the present study, we characterize the GVs for the development of green biopesticide formulation to manage sugarcane borers.

Larvae of shoot and internode borers were collected from sugarcane fields of Coimbatore and its surroundings in Tamil Nadu, South India. The insects were reared on sugarcane shoot bits or internode bits. The infected larvae became restless and fed voraciously in the early stage of infection. They appeared robust with pale integument. As the infection progressed, the larvae became lethargic and ceased feeding. During rearing, larvae showing characteristic symptoms of infection with $\mathrm{GVs}$ were isolated and reared separately. The skin of the moribund larvae turned white, except in the intersegmental zone. Dead larvae were collected and put in individual sterile vials. Cadavers were labelled individually and used for extraction of GVs. Occlusion bodies (OBs) of GVs were extracted from the virosed larvae according to the standard procedure ${ }^{7}$ and stored at $4^{\circ} \mathrm{C}$ till further use. The viruses were confirmed by the presence of OBs in the discharged 